\title{
APPLICATION OF THE RULINGS \\ OF THE CONSTITUTIONAL COURT OF THE RUSSIAN FEDERATION IN SUPERVISING COMPLIANCE WITH THE FEDERAL LEGISLATION BY THE PROSECUTOR'S OFFICE OF THE RUSSIAN FEDERATION
}

\author{
Alexey V. Ushakov \\ Prosecutor's Office of Voroshilovsky District of Volgograd, Volgograd, Russian Federation
}

Introduction: the paper is devoted to identifying the features of interaction between the Constitutional Court of the Russian Federation and the Prosecutor's Office, as well as the application of the Court's rulings in the supervision of compliance with the legislation of the Russian Federation. For this purpose, the author studies the information about the application of the rulings of the Constitutional Court of the Russian Federation in the supervision of compliance with the law, as well as the practice of formulating the Court's rulings on the activities of the Prosecutor's Office. Using the methods of scientific knowledge, first of all, the method of system analysis of judicial and legal acts, the author comes to the need to improve the efficiency of this process. Results: the author points out the need to intensify the practice of applying the rulings of the Constitutional Court of the Russian Federation in the protection of citizens' rights by the Prosecutor's Office of the Russian Federation. Conclusions: according to the author, the implementation of the decisions and rulings of the Constitutional Court of the Russian Federation by the Prosecutor's Office in the supervisory activities will ensure the necessary state of the legality in public relations.

Key words: Prosecutor's Office of the Russian Federation, Constitutional Court of the Russian Federation, ruling, supervision of compliance with the Federal legislation.

Citation. Ushakov A.V. Application of the Rulings of the Constitutional Court of the Russian Federation in Supervising Compliance with the Federal Legislation by the Prosecutor's Office of the Russian Federation. Legal Concept, 2020, vol. 19, no. 1, pp. 80-85. (in Russian). DOI: https://doi.org/10.15688/lc.jvolsu.2020.1.11

\section{ПРИМЕНЕНИЕ ПРАВОВЫХ ПОЗИЦИЙ КОНСТИТУЦИОННОГО СУДА РОССИЙСКОЙ ФЕДЕРАЦИИ ПРИ ОСУЩЕСТВЛЕНИИ НАДЗОРА ЗА СОБЛЮДЕНИЕМ ФЕДЕРАЛЬНОГО ЗАКОНОДАТЕЛЬСТВА ОРГАНАМИ ПРОКУРАТУРЫ РОССИЙСКОЙ ФЕДЕРАЦИИ}

\author{
Алексей Викторович Ушаков \\ Прокуратура Ворошиловского района г. Волгограда, г. Волгоград, Российская Федерация
}

\footnotetext{
을 Ведение: статья посвящена выявлению особенностей взаимодействия Конституционного Суда РФ и ণ્ટે органов прокуратуры, а также применения правовых позиций Суда при осуществлении надзора за соблюдением законодательства РФ. С этой целью автор изучает сведения о применении правовых позиций Конституционного Суда РФ при осуществлении надзора за соблюдением законодательства, а также практику формуоै лирования правовых позиций суда по вопросам деятельности органов прокуратуры. С помощью методов научного познания, в первую очередь метода системного анализа судебных и нормативно-правовых актов, автор приходит к необходимости повышения эффективности этого процесса. Результаты: автором указыва() ется на необходимость активизации практики применения правовых позиций Конституционного Суда РФ
} 
при осуществлении защиты прав граждан органами прокуратуры Российской Федерации. Выводы: реализация органами прокуратуры в надзорной деятельности решений и изложенных в них правовых позиций Конституционного Суда РФ обеспечит необходимое состояние законности в общественных отношениях.

Ключевые слова: Прокуратура Российской Федерации, Конституционный Суд РФ, правовая позиция, надзор за соблюдением федерального законодательства.

Цитирование. Ушаков А. В. Применение правовых позиций Конституционного Суда Российской Федерации при осуществлении надзора за соблюдением федерального законодательства органами прокуратуры Российской Федерации // Legal Concept = Правовая парадигма. - 2020. - T. 19, № 1. - C. 80-85. - DOI: https://doi.org/10.15688/lc.jvolsu.2020.1.11

\section{Введение}

В своей деятельности органы прокуратуры тесно взаимодействуют с Конституционным Судом РФ, исполнение решений которого оказывает существенное воздействие на состояние законности. В сфере судебно-конституционного процесса полномочия органов прокуратуры определены законодателем лишь в связи с необходимостью реализации полномочий в области защиты конституционных прав и свобод граждан, нарушения которых допущены законом, примененным либо подлежащим применению в конкретной правовой ситуации.

\section{Нормативно-правовое регулирование конституционно-правового статуса органов прокуратуры}

Прокуратура Российской Федерации в системе органов государственной власти России занимает особое положение: по Конституции Российской Федерации она представляет собой инструмент системы сдержек и противовесов, в связи с чем постоянно и тесно взаимодействует со всеми органами государственной власти, в том числе и судебными [5].

В силу п. 6 ст. 35 Федерального закона «О прокуратуре Российской Федерации» предусмотрено право обращаться в Конституционный Суд Российской Федерации для Генерального прокурора Российской Федерации в связи с нарушением конституционных прав и свобод граждан законом, примененным или подлежащим применению в конкретном деле [9].

Правовая позиции Конституционного Суда Российской Федерации, изложенная в постановлении от 18 июля 2003 г. № 13-П, заключает: «...В соответствии с законодательно закрепленной целью деятельности прокурату- ры Российской Федерации - обеспечением верховенства законов на всей территории Российской Федерации (пункт 2 статьи 1 Федерального закона "О прокуратуре Российской Федерации”) федеральный законодатель... наделил органы прокуратуры полномочием по надзору за соблюдением Конституции Российской Федерации и исполнением федеральных законов, в частности законодательными (представительными) и исполнительными органами субъектов Российской Федерации, а также за соответствием Конституции Российской Федерации, федеральным конституционным законам и федеральным законам издаваемых этими органами правовых актов, в том числе конституций (уставов)» [7].

С одной стороны, как отмечает С.Э. Несмеянова, «Конституция Российской Федерации не предусматривает Генерального прокурора Российской Федерации в качестве субъекта, обладающего правом обращения в Конституционный Суд Российской Федерации с запросом о проверке законов и иных нормативных правовых актов. С другой точки зрения, федеральный законодатель позволил обращаться в Конституционный Суд РФ Генеральному прокурору Российской Федерации с целью их защиты и реализации уже существующих правовых позиций Конституционного Суда России [6].

В 2008 г. в связи с переездом Конституционного Суда РФ в г. Санкт-Петербург и в целях улучшения взаимодействия Суда и органов прокуратуры представитель надзорного органа участвует в каждом заседании и излагает свое мнение в форме заключения по рассматриваемым в суде вопросам [1, с. 68].

Более ярко и последовательно процесс применения правовых позиций, изложенных в решениях Конституционного Суда Российской Федерации, реализуется в практике прокурор- 


\section{ТЕОРИЯ И ПРАКТИКА ГОСУДАРСТВЕННО-ПРАВОВОГО РАЗВИТИЯ}

ского надзора в сфере защиты прав и законных интересов человека и гражданина. Более того, защита основных социально-экономических прав и свобод является одним из приоритетных направлений «общенадзорной» деятельности российской прокуратуры.

Предмет прокурорского надзора составляет соблюдение органами государственной власти и местного самоуправления, органами контроля, юридическими лицами Конституции Российской Федерации и исполнение законов, соответствия законам принимаемых ими правовых актов. Содержание прокурорского надзора заключается в обеспечении необходимого правового режима законности в деятельности поднадзорных объектов.

Согласно п. 14 Приказа Генерального прокурора Российской Федерации № 475 от 10 июля 2017 г. «Об обеспечении участия прокуроров в гражданском и административном судопроизводстве», при рассмотрении обращений о проверке вступивших в законную силу судебных актов по делам, в которых предусмотрено участие прокурора, надлежит руководствоваться требованиями ГПК РФ, КАС РФ, законодательством, регулирующим спорные правоотношения, решениями Конституционного Суда Российской Федерации и судебной практикой Европейского Суда по правам человека и Верховного Суда Российской Федерации [10].

Таким образом, при организации прокурорского надзора в сфере защиты прав граждан, интересов государства решения Конституционного Суда Российской Федерации, а следовательно и изложенные в них правовые позиции определены в качестве базовых начал, которыми необходимо руководствоваться прокурорскому работнику при рассмотрении обращений граждан, а также при проверке судебных актов по гражданским делам с участием прокурора.

В ходе проведенных исследований автором проведено анкетирование 132 сотрудников районных и городских прокуратур, расположенных на территории Южного федерального округа. При этом, как показали результаты анкетирования, $97 \%$ опрошенных прокурорских работников в своей надзорной деятельности применяют правовые позиции Конституционного Суда РФ, для 94,7 \% уча- стников анкетирования в связи с применением правовых позиций разрешаются многие спорные вопросы применения федерального законодательства.

\section{Правовые позиции}

\section{Конституционного Суда РФ по вопросам реализации прокурором своих полномочий}

Реализация прокурором своих полномочий неоднократно была предметом рассмотрения Конституционного Суда РФ.

Проведенное исследование показало, что сформулированные правовые позиции касались вопросов реализации прав прокурорских работников на судебную защиту (Постановление Конституционного Суда РФ от 16 апреля 1993 г. № 7-П), реализации полномочий в отношении депутатов региональных представительных органов власти (Постановление Конституционного Суда РФ от 30 ноября 1995 г. № 16-П), реализации полномочий по обращению в суд с заявлением о проверке соответствия закона субъекта РФ федеральному закону (Постановление Конституционного Суда РФ от 11 апреля 2000 г. № 6-П), по вопросу привлечения депутатов региональной власти к ответственности (Постановление Конституционного Суда РФ от 12 апреля 2002 г. № 9-П), реализации полномочий в уголовном производстве (Постановление Конституционного Суда РФ от 8 декабря 2003 г. № 18-П) [6].

В контексте обсуждения вопросов применения правовых позиций конституционного правосудия при реализации прокурором своих полномочий в сфере надзора за соблюдением прав и свобод человека и гражданина вызывает интерес правовая позиция, сформулированная Конституционным Судом РФ в Постановлении от 17 февраля 2015 г. № 2-П по делу о проверке конституционности положений п. 1 ст. 6 , п. 2 ст. 21 , п. 1 ст. 22 Федерального закона «О прокуратуре Российской Федерации». Судом в ходе анализа норм федерального закона постановлено, что федеральному законодателю надлежит внести в правовое регулирование полномочий прокурора изменения, а именно - необходимо определить конкретные предельные сроки проведения проверочных мероприятий и сроки исполнения проверяемыми организациями требований прокурора, вы- 
текающих из его полномочий. Во исполнение указанного постановления Конституционного Суда РФ Федеральным законом от 7 марта 2017 г. № 27-Ф3 «О внесении изменений в Федеральный закон "О прокуратуре Российской Федерации"» внесены изменения, которыми скорректированы полномочия, порядок и сроки проведения прокурорских проверок [10].

Итоговые решения Конституционного Суда РФ своевременно доводятся до сведения Генерального прокурора РФ в целях информирования об их содержании. Согласно ст. 77 Федерального конституционного закона Российской Федерации № 1-ФКЗ «О Конституционном Суде Российской Федерации», постановления и заключения Суда не позднее чем в двухнедельный срок со дня их подписания направляются Генеральному прокурору России с целью уведомления о содержании принятого решения и ускорения процесса его исполнения [4]. Это осуществляется для того, чтобы обеспечить реальность направленности правовых позиций Конституционного Суда России путем осуществления активных действий и решений, направленных на устранение неконституционной правовой нормы.

\section{Применение правовых позиций Конституционного Суда РФ} при осуществлении органами прокуратуры надзора за исполнением законов

\section{и законностью правовых актов}

Вопросы устранения названных пробелов и недостатков в законодательстве находятся на постоянном контроле у органов прокуратуры. В ходе проведения исследования автором изучена надзорная практика в области обеспечения законности региональных нормативно-правовых актов.

С целью обеспечения единства правового пространства органы прокуратуры исходят из необходимости своевременного пресечения фактов незаконного нормотворчества. Как правило, надзор за соблюдением федерального законодательства в этом направлении носит упреждающий характер.

Например, прокуратурой региона при осуществлении надзорных полномочий изучен проект регионального закона «О порядке орга- низации и ведения регистра муниципальных нормативных правовых актов...» [2].

Статьей 6 проекта закона устанавливается 30-дневный срок предоставления сведений из регионального муниципального регистра по запросу заинтересованного лица, а также требования к форме и содержанию такого запроса. Однако из содержания указанных в ней норм неясно, к какому именно кругу лиц они могут быть применимы, распространяют ли они свое действие на запросы должностных лиц, осуществляющих свои полномочия на основании и в порядке, установленном федеральным законодательством (прокурор, судья, следователь и др.).

Вместе с тем из правовой позиции Конституционного Суда Российской Федерации, изложенной в Постановлении от 17 июня 2004 г. № 12-П, следует, что конституционный принцип равенства (ст. 19, ч. 1, Конституции Российской Федерации) требует определенности, ясности и недвусмысленности законодательного регулирования, поскольку такое равенство может быть обеспечено лишь при условии единообразного понимания и толкования правовой нормы всеми правоприменителями [4].

При рассмотрении акта прокурорского реагирования доводы прокуратуры учтены региональным законодателем - проект закона в указанной редакции разработчиком был отозван.

Прокуратура, как верно отмечает М.В. Баглай, просто обязана в случае, если нарушается какое-нибудь нормативное положение, и тем более исходящее из решения Конституционного Суда, защитить человека, обратиться в суд с требованием, чтобы это было исправлено [3].

В целом органами прокуратуры в сфере защиты конституционных социально-экономических прав граждан проводится значительная работа. Так, в рамках защиты прав и свобод человека и гражданина органами прокуратуры региона в 2019 г. выявлено свыше 27 тыс. нарушений, для устранения которых принесено порядка 5000 протестов на незаконные правовые акты, внесено свыше 8000 представлений об устранении нарушений законодательства, в интересах социально незащищенных слоев населения и государственных интересах предъявлено и рассмот- 


\section{ТЕОРИЯ И ПРАКТИКА ГОСУДАРСТВЕННО-ПРАВОВОГО РАЗВИТИЯ}

рено свыше 3000 исковых заявлений о защите прав граждан и законных интересов, по материалам проверок привлечено к дисциплинарной ответственности 8000 должностных лиц, а к административной - свыше 1700 , по результатам прокурорских проверок возбуждено 100 уголовных дел [8].

\section{Выводы}

Приведенный анализ практики взаимодействия органов прокуратуры и Конституционного Суда РФ при осуществлении надзора за соблюдением федерального законодательства, а также в целях защиты прав граждан свидетельствует о том, что надзорный орган, реализуя свои полномочия, в том числе основываясь на содержании решений и правовых позиций Конституционного Суда РФ, в своей деятельности является самостоятельным органом надзора за соблюдением Конституции РФ, федерального законодательства, обеспечения защиты прав и свобод человека и гражданина. При этом прокуратура, не являющаяся звеном судебной или исполнительной власти, посредством реализации надзорных полномочий обеспечивает особое правовое состояние общественных отношений - состояние законности - и тем самым выполняет роль важнейшего элемента системы сдержек и противовесов.

\section{СПИСОК ЛИТЕРАТУРЫ}

1. Васильева, Т. А. Участие прокурора в конституционном судопроизводстве: проблемы законодательства и правоприменения / Т.А. Васильева // Вестник Академии Генеральной прокуратуры РФ. - 2013. - № 5 (37). - С. 68-76.

2. Волгоградская областная Дума : [офиц сайт]. - Электрон. текстовые дан. - Режим доступа: https://volgoduma.ru/information/news/ (дата обращения: 02.01.2020). - Загл. с экрана.

3. Интернет-конференция Председателя Конституционного Суда Российской Федерации Баглая М. В. «К 10-летию Конституции Российской Федерации : защита конституционных прав и свобод граждан». - Электрон. текстовые дан. - Режим доступа: http://www.garant.ru (дата обращения: 12.04.2019). Загл. с экрана

4. Конституционный Суд Российской Федерации: официальный сайт. - Электрон. текстовые дан. - Режим доступа: http://www.ksrf.ru (дата обращения: 02.01.2020). - Загл. с экрана.

5. Конституция Российской Федерации : принята всенародным голосованием 12 декабря 1993 г. (с учетом поправок, внесенных ФКЗ Российской Федерации о поправках к Конституции Российской Федерации от 30 декабря 2008 г. № 6-ФКЗ, от 30 декабря 2008 г. № 7- ФКЗ) // Собрание законодательства Российской Федерации. - 2009. - № 4. - Ст. 445.

6. Несмеянова, С. Э. Судебная практика Конституционного Суда Российской Федерации с комментариями / С. Э. Несмеянова. - М. : Проспект, 2008. $-478 \mathrm{c}$.

7. Постановление Конституционного Суда Российской Федерации от 18.07.2003 № 13-П «По делу о проверке конституционности положений статей 115 и 231 ГПК РСФСР, статей 26, 251 и 253 ГПК Российской Федерации, статей 1, 21 и 22 Федерального закона "О прокуратуре Российской Федерации" в связи с запросами Государственного Собрания - Курултая Республики Башкортостан, государственного Совета Республики Татарстан и Верховного Суда Республики Татарстан» // Собрание законодательства Российской Федерации. 2003. - № 30. - Ст. 3101.

8. Прокуратура Волгоградской области : [офиц. сайт]. - Электрон. текстовые дан. - Режим доступа: https://volgoproc.ru/ (дата обращения: 02.01.2020). - Загл. с экрана.

9. Федеральный закон № 2202-1 от 17 января 1992 г. «О прокуратуре Российской Федерации» // Ведомости Съезда народных депутатов Российской Федерации и Верховного Совета Российской Федерации. - 1992. - № 8. - Ст. 366.

10. Федеральный закон от 7 марта 2017 г. №27-Ф3 «О внесении изменений в Федеральный закон “О прокуратуре Российской Федерации”». - Электрон. текстовые дан. - Режим доступа: http://www.garant.ru/ hotlaw/federal/1096136/\#ixzz6JraQgYuu (дата обращения: 02.01.2020). - Загл. с экрана.

\section{REFERENCES}

1. Vasilyeva T.A. Uchastie prokurora $\mathrm{v}$ konstitutsionnom sudoproizvodstve: problemy zakonodatelstva i pravoprimeneniya [A Prosecutor's Participation in the Constitutional Proceedings: Legislation and Law Enforcement Issues]. Vestnik Akademii Generalnoy prokuratury RF [Bulletin Academy of the R.F. Prosecutor General's Office], 2013, no. 5(37), pp. 68-76.

2. Volgogradskaya oblastnaya Duma [Volgograd Regional Duma]. URL: https://volgoduma. ru/information/news/ (accessed 2 January 2020).

3. Internet-konferentsiya Predsedatelya Konstitutsionnogo Suda Rossiyskoy Federatsii 
Baglaya M.V. «K 10-letiyu Konstitutsii Rossiyskoy Federatsii: zashchita konstitutsionnykh prav i svobod grazhdan» [Internet Conference of Chairman of the Constitutional Court of the Russian Federation Baglaya M.V. "To the $10^{\text {th }}$ Anniversary of the Constitution of the Russian Federation: Protection of Constitutional Rights and Freedoms of Citizens"]. URL: http://www.garant.ru (accessed 12 April 2019).

4. Konstitutsionnyy Sud Rossijykoy Federatsii [Constitutional Court of the Russian Federation]. URL: http://www.ksrf.ru (accessed 2 January 2020).

5. Konstitutsiya Rossiyskoy Federatsii: prinyata vsenarodnym golosovaniem 12 dekabrya $1993 \mathrm{~g}$. (s uchetom popravok, vnesennykh FKZ Rossiyskoy Federatsii o popravkakh k Konstitutsii Rossiyskoy Federatsii ot 30 dekabrya 2008 g. № 6-FKZ, ot 30 dekabrya 2008 g. № 7-FKZ [Constitution of the Russian Federation: Adopted by Nation-Wide Voting on December 12, 1993 (Including Amendments to the Constitutional Law of the Russian Federation on Amendments to the Constitution of the Russian Federation of December 30, 2008 no. 6-FKZ, of December 30, 2008 no. 7-FKZ)]. Sobranie zakonodatelstva Rossiyskoy Federatsii, 2009, no. 4, art. 445.

6. Nesmejanova C.Je. Sudebnaya praktika Konstitutsionnogo Suda Rossiyskoy Federatsii s kommentariyami [Court Practice of the Constitutional Court of the Russian Federation with Comments]. Moscow, Prospekt Publ., 2008. 478 p.

7. Postanovlenie Konstitutsionnogo Suda Rossiyskoy Federatsii ot 18.07.2003 № 13-P «Po delu o proverke konstitutsionnosti polozheniy statey $115 \mathrm{i}$ 231 GPK RSFSR, statey 26, 251 i 253 GPK Rossiyskoy Federatsii, statey 1, 21 i 22 Federalnogo zakona "O prokurature Rossiyskoy Federatsii" v svyazi c zaprosami Gosudarstvennogo Sobraniya - Kurultaya Respubliki Bashkortostan, gosudarctvennogo Soveta Respubliki Tatarstan i Verkhovnogo Suda Respubliki Tatarstan [Decision of the Constitutional Court of the Russian Federation Dated July 18, 2003 no. 13-P"With Regard to the Case on the Verification of Constitutionality of Provisions of Articles 115 and 231 of the Civil Procedure Code of the Russian Soviet Federative Socialist Republic, Articles 26, 251 and 253 of the Civil Procedure Code of the Russian Federation, Articles 1, 21 and 22 of the Federal Law "On the Prosecutor's Office of the Russian Federation" in Connection with Inquiries of the State Council Kurultai of the Republic of Bashkortostan, State Council of the Republic of Tatarstan and the Supreme Court of the Republic of Tatarstan"]. Sobranie zakonodatelstva Rossiyskoy Federatsii, 2003, no. 30, art. 3101.

8. Prokuratura Volgogradskoy oblasti [Prosecutor's Office of Volgograd Region]. URL: https://volgoproc.ru/ (accessed 2 January 2020).

9. Federalnyy zakon № 2202-1 ot 17 yanvarya 1992 g. «O prokurature Rossiyskoy Federatsii» [Federal Law no. 2202-1 of January 17, 1992 "On the Prosecutor's Office of the Russian Federation"]. Vedomosti Syezda narodnykh deputatov Rossiyskoy Federatsii $i$ Verkhovnogo Soveta Rossiyskoy Federatsii, 1992, no. 8, art. 366.

10. Federalnyy zakon ot 7 marta 2017 g. № $27-F Z$ "O vnesenii izmeneniy $v$ Federalnyy zakon "O prokurature Rossiyskoy Federatsii"” [Federal Law of March 7, 2017 no. 27-FZ “On Amendments to the Federal Law 'On the Prosecutor's Office of the Russian Federation"']. URL: http://www.garant.ru/ hotlaw/federal/1096136/ (accessed 2 January 2020).

\section{Information About the Author}

Alexey V. Ushakov, Prosecutor, Prosecutor's Office of Voroshilovsky District of Volgograd, Barrikadnaya St., 23, 400074 Volgograd, Russian Federation, ushakov_alex@mail.ru, https://orcid.org/ 0000-0003-0282-7602

\section{Информация об авторе}

Алексей Викторович Ушаков, прокурор, прокуратура Ворошиловского района г. Волгограда, ул. Баррикадная, 23, 400074 г. Волгоград, Российская Федерация, ushakov_alex@mail.ru, https://orcid.org/0000-0003-0282-7602 